\title{
Fatigue and Fracture of Friction Stir Linear Welded Dissimilar Aluminum-to-Magnesium Alloys
}

\author{
H.M. Rao ${ }^{1}$, J.B. Jordon ${ }^{1 *}$, B. Ghaffari ${ }^{2}$, X. Su${ }^{2}$, A.K. Khosrovaneh ${ }^{3}$, M.E. Barkey ${ }^{4}$ \\ W. Yuan ${ }^{5}$, M. Guo \\ ${ }^{1}$ Department of Mechanical Engineering, The University of Alabama, AL 35487, USA \\ ${ }^{2}$ Ford Research and Innovation Center, Ford Motor Company, Dearborn, MI 48124, USA \\ ${ }^{3}$ General Motors Company, Warren, MI 48090, USA \\ ${ }^{4}$ Department of Aerospace Engineering and Mechanics, The University of Alabama, AL 35487, \\ USA \\ ${ }^{5}$ Hitachi America Ltd., R\&D Division, Automotive Products Research Laboratory, Farmington \\ Hills, MI 48335, USA \\ ${ }^{6}$ FCA US LLC, MI 48326, USA \\ Keywords: Friction Stir Welding; Dissimilar alloys; Fatigue \\ *corresponding author. Phone: 205.348.2701; E-mail address: bjordon@eng.ua.edu
}

\begin{abstract}
A comprehensive study of fatigue life and damage mechanisms of friction stir linear welded dissimilar aluminum-to-magnesium alloys in lap-shear configuration is presented. The overlap linear welds were created by welding AA6022 aluminum alloy to AM60B magnesium alloy. The test results showed significant scatter in the fatigue life and the corresponding fracture modes. Two distinct modes of failure were observed for the lap-shear specimens. In one of the failure modes observed, fracture occurred when the dominant fatigue crack propagated into either the magnesium or aluminum sheet in a kink-crack formation. In addition, fretting debris was found at locations of crack initiation for this fracture mode. In the other observed mode of failure, fracture occurred by interfacial weld separation, where fractography analysis suggests that the fatigue cracks initiated at weld defects and then propagated through the brittle intermetallic phase formed during welding.
\end{abstract}

(C) 2015. This manuscript version is made available under the Elsevier user license http://www.elsevier.com/open-access/userlicense/1.0/ 


\section{Introduction}

While resistance spot welding and low temperature fusion welding are options for magnesium-to-magnesium joining, the joining of magnesium to dissimilar metals presents a significant problem in the manufacturing industry. Without a robust technique for dissimilar joining, introduction of more magnesium components is not feasible for multitude of industries. Over the years, research studies have established the friction stir welding (FSW) technique as an efficient methodology to weld magnesium alloys. Most research on FSW has been relatively limited to the joining of similar magnesium-to-magnesium alloys or aluminum-to-aluminum alloys. Previous studies have established the influence of welding process parameters on the micro and macro features of the weld and how these features affect the weld strength in FSW joints [1-12].

A key challenge in using dissimilar materials arises during the assembly and joining process. Applying heat and force during the welding process leads to the formation of brittle and structurally frail intermetallic compounds (IMCs). During the FSW of magnesium and aluminum alloys, constitutional liquation occurs in the weldment, which leads to formation of these IMCs $\left(\mathrm{Al}_{12} \mathrm{Mg}_{17}, \mathrm{Al}_{3} \mathrm{Mg}_{2}\right)$ in the stir zone [13-22]. Most studies on FSW of dissimilar alloys have discussed the formation of IMCs and the corresponding poor quasi-static strength of the welds [14,16,19,20,23-27]. However, recent results [28,29] have established the feasibility of producing strong FSW joints of magnesium to aluminum alloys, inviting a closer examination of the possibilities. Typically, in real-world applications, welded joints are subjected to fatigue loading and hence, it is imperative to study the fatigue behavior of these dissimilar welded joints. In one of the few existing studies on the fatigue of dissimilar FSW joints [30], the fatigue life of friction stir spot welded (FSSW) dissimilar magnesium-to-aluminum joints was much lower than 
the fatigue life of similar FSSW joints. The other work on the fatigue behavior of dissimilar friction stir welded joints is largely based on the joining of dissimilar aluminum-to-aluminum alloys [31-36]. In light of the above-mentioned encouraging quasi-static results, for which the adverse effects of the IMCs seem to have been minimized, this work aims to study the fatigue life of friction stir linear welded (FSLW) aluminum-to-magnesium alloys. As such, this is the

first study to investigate the fatigue life properties and failure modes in dissimilar FSLW of aluminum-to-magnesium alloys.

\section{Materials and Methods}

Rolled AA6022-T4 aluminum alloy sheets of $1.5 \mathrm{~mm}$ in thickness were joined using FSLW to super vacuum die cast AM60B magnesium alloy sheets of thickness $3.1 \mathrm{~mm}$. The FSLW tool, shown in Fig. 1a, was made of standard tool steel (H13) and constituted a concave tool shoulder with a diameter of $12 \mathrm{~mm}$ and a smooth-surface triangular pin with an equivalent triangle diameter of $5.4 \mathrm{~mm}$ and a pin length of $2.4 \mathrm{~mm}$. The aluminum sheet was stacked on top of the magnesium sheet in lap-shear configuration with an overlap area of $152.4 \mathrm{~mm} \times 30 \mathrm{~mm}$, as shown in Fig. 1b. Two stitch welds, each measuring $55 \mathrm{~mm}$ in length, were produced per plate in order to evaluate the welds for automotive applications. After producing the first weld (W1), the tool would retract and traverse $15 \mathrm{~mm}$ in air and plunge back into the top of the aluminum sheet to produce the second weld (W2). A thorough investigation of the FSLW parameters was conducted $[28,29]$ to optimize the weld lap-shear quasi-static load, and to obtain a measure of the process robustness. Metallurgical cross sections of the specimens were utilized to examine the material flow in the welded region and to establish that the triangular shape of the welding pin seems to break up the unavoidable IMCs that form at the faying surface, leading to the observed superior quasi-static load. Per these investigations, all welds for the present study were produced 
at a tool rotation rate of $1500 \mathrm{rpm}$, a tool traverse speed of $75 \mathrm{~mm} / \mathrm{min}$, a tool shoulder plunge depth of $0.3 \mathrm{~mm}$ and the tool tilt angle was maintained at 3 degrees. The tool traversed from the right of the weld setup to the left, as indicated by the bold arrows in Fig. 1b; whereas the dotted arrows around $\mathrm{W} 1$ and $\mathrm{W} 2$ indicate the tool rotation direction (counterclockwise). This was to ensure the welds would have the advancing side (AS) at the free end of the coupon and the retreating side (RS) was on the loading side of the coupon, as shown in Fig. 1b and Fig. 1c. To measure the quasi-static and fatigue properties of the welds, test coupons, each measuring $30 \mathrm{~mm}$ in width, were water-jet cut from both W1 and W2. Only the lap-shear coupons without keyholes were studied for fatigue properties. The final dimensions of the lap-shear test coupons are shown in Fig. 1c. Since these welds could potentially be part of a larger component in an automotive application, which would be subjected to paint baking, the test coupons were baked in a forced convection oven at $180^{\circ} \mathrm{C}$ for 30 minutes.

For weld characterization, samples were sectioned through the center of the nugget and parallel to the loading direction. The samples were cold mounted in epoxy and were mechanically ground and fine polished using $0.05 \mu \mathrm{m}$ alumina. Since two different materials (aluminum and magnesium) were polished simultaneously, only de-ionized water was used during the polishing steps. In order to reveal the microstructure and IMCs, AM60B was etched

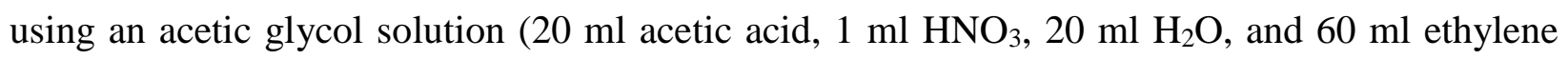
glycol), while the AA6022-T4 was etched with a caustic etchant (20\% NaOH solution) [27]. The microstructures of the welds were analyzed using a Keyence VHX-1000 digital optical microscope. Typical optical micrographs of the stir zone (SZ), thermomechanically-affected zone (TMAZ), heat-affected zone (HAZ) and base metal were obtained. Representative fatigued lap-shear coupons were also observed under the Keyence microscope to identify the failure 
modes and fracture surfaces. In addition, the fracture surfaces of fatigue-tested lap-shear coupons were examined under a Jeol 7000 scanning electron microscope (SEM) to investigate the fracture surface, crack propagation and obtain chemical analysis using energy-dispersive X-ray spectroscopy (EDX).

Microhardness measurements of representative lap-shear coupons were performed on a Wilson hardness testing machine. A load of $100 \mathrm{~g}$ and dwell time of $5 \mathrm{~s}$ were employed to measure the Vickers hardness (HV). Hardness measurements were recorded for the aluminum and magnesium sheets starting outside the HAZ and then traversing towards the other side of the weld. A total of 55 indents were made on each sheet with a spacing of $0.5 \mathrm{~mm}$.

For the fatigue tests, a total of 48 lap-shear coupons were cyclically tested on a MTS servo-hydraulic load frame in load control with a sinusoidal wave profile. The lap-shear coupons were all tested at a load ratio of 0.1 and below the average quasi-static ultimate tensile strength of the lap-shear coupons, which is approximately $3500 \mathrm{~N}$. The fatigue load range tested was between a maximum of $3150 \mathrm{~N}(90 \%$ of $3500 \mathrm{~N})$ and a minimum of $1155 \mathrm{~N}(33 \%$ of $3500 \mathrm{~N})$. The fatigue tests were conducted at a frequency of $20 \mathrm{~Hz}$. Shims were employed on the lap-shear coupons during the testing (refer to Fig. 1c) to avoid additional bending moments and loads. The grip-to-grip distance was maintained at $63 \mathrm{~mm}$ for each lap-shear coupon.

\section{Results and Discussion}

\subsection{Microstructural Characterization and Microhardness}

A representative etched cross-section of an untested FSLW dissimilar aluminum-tomagnesium coupon is shown in Fig. 2a. In Fig. 2b, the dotted lines indicate the sharp transition from the SZ to TMAZ, and the TMAZ to the HAZ located on the RS of the weld in the 
aluminum side of the weld. A clear distinction between the fine grains of the SZ, the deformed grains of the TMAZ, and large recrystallized grains in HAZ is clearly visible. Due to the dynamically recrystallized grains in the SZ, fine grains were observed, as shown in Fig. 2c. Likewise, on the AS of the weld, the black dotted lines in Fig. $2 \mathrm{~d}$ show the transition from the SZ to the TMAZ, and from the TMAZ to the HAZ. Directly under the stir zone in the magnesium side of the weld, only minor microstructural changes were observed due to the shallow plunge of the tool pin and the resulting the lower temperature (as shown Fig 2e). In the magnesium side of the weld, the TMAZ is characterized by highly deformed grains while the HAZ is characterized by larger recrystallized grains.

Figure 3 shows the Vickers microhardness measurements for both the aluminum and magnesium sides of the weld. These results illustrate the large difference in hardness between the two different alloys. The microhardness measurements also show that the HAZ is the softest region of the weld as indicated by the dips in the curves of both the magnesium and aluminum sheets (located around $\pm 5 \mathrm{~mm}$ from the center of the weld). Interestingly, the FSLW process leads to a reduction in the hardness of the $\mathrm{SZ}$ of the aluminum side of the weld compared to the base metal, while in the magnesium sheet, the FSLW resulted in higher hardness measurements in the SZ. This higher hardness measurement is due to the recrystallization of the dendritic grains in the cast magnesium alloy.

Observations of the lap-shear FSLW coupons under SEM revealed a thin layer of IMCs at the interface of the aluminum and magnesium sheet. Shown in Fig. 4a is the cross section of a typical FSLW, and the rectangular boxes indicate the regions S1, S2, S3 and S4, where chemical characterization using energy-dispersive X-ray spectroscopy was performed. EDX results in these regions indicate that the IMCs are composed of a sandwich layer of $\mathrm{Al}_{3} \mathrm{Mg}_{2}$ on the 
aluminum side and $\mathrm{Al}_{12} \mathrm{Mg}_{17}$ on the magnesium side. Figures $4 \mathrm{~b}$ and $4 \mathrm{c}$ show that the $\mathrm{IMC}$ layer is approximately 2-3 $\mu \mathrm{m}$ in thickness on the RS of the weld. However, on the AS of the weld, the IMC layer is approximately $5-6 \mu \mathrm{m}$ in thickness. This thicker IMC layer is due to the higher frictional heat input on the AS of the weld compared to that on the RS of the weld [37]. Previous studies have indicated that if the two faying surfaces are held close to each other and under high temperature, diffusion of the atoms will occur, thus forming the IMCs [15,24]. While not shown, it is important to note that the IMCs layer on the faying surface was not observed beyond the width of tool shoulder on RS and AS of the weld. This proves the downward forging force applied by the tool shoulder during the welding process facilitates the formation of IMCs at the faying surface.

\subsection{Fatigue and Fracture}

The experimental results for the FSLW lap-shear fatigue testing are shown in Fig. 5, where in general, the fatigue results exhibited a wide scatter. Note that the arrows indicate runout and different symbols and colors are used to represent the various fracture modes. The particularly large scatter at fatigue loads above $2,500 \mathrm{~N}$ seems reasonable since the applied fatigue load is approaching the peak quasi-static lap-shear strength of the joint. Under fatigue testing, the dissimilar FSLW lap-shear welds were observed to fail in three main fracture modes as shown in Fig. 6: kink-crack failure of the magnesium sheet (Fig. 6a); kink-crack failure of the aluminum sheet (Fig. 6b); and interfacial weld failure (Fig. 6c). Regarding the kink-crack failure modes, which appear similar to the eyebrow failure in spot welds, the dominant crack was observed to initiate at the faying surface and then propagate either into the magnesium sheet on the AS of the weld or into the aluminum sheet on the RS of the weld. In contrast, the more commonly observed failure mode occurred when the dominant crack propagated through the SZ 
of the weld in a shear mode, which resulted in an interfacial failure. It is apparent from Fig. 5 that at higher fatigue loads $(>2,000 \mathrm{~N})$ interfacial failure of the weld is the dominant fracture mode. This type of failure is reasonable considering the presence of the brittle IMCs and the high applied fatigue loading. As shown in Fig. 5, below 2,000 $\mathrm{N}$ of applied fatigue loading, all three fracture modes were observed and no clear trend was observed between the number of cycles to failure and fracture modes. However, very near to run-out loading, the fracture of the coupons occurred in the aluminum sheet. Thus, it appears that when the stress on the joint is relatively low, the brittle nature of the IMCs is not a dominant factor, and thus failure occurs by kink-crack fracture. The nature of the crack initiation of these kink-cracks will be discussed later.

Failed fatigue samples were cross-sectioned and mounted for observation under optical light microscopy. Figure 7a shows a representative cross-sectional view of a FSLW coupon that failed in the magnesium sheet. As noted earlier, the dominant fatigue crack that led to failure in this particular fracture mode propagated in kink manner into the magnesium sheet (Fig. 7b). It is important to note that the crack initiated at the boundary of the AS faying surface. While the magnesium sheet contains casting pores, it is unclear what influence these casting pores had on the total number of cycles to failure. However, it seems reasonable that at near run-out loadings, the influence of the casting pores in the magnesium sheet was minimal, thus leading to a higher local stress concentration in the aluminum sheet.

Figure 8a shows a cross-sectional view of an aluminum sheet failure, where the dominant crack propagated in a kink manner into the aluminum sheet. All failures of this type were observed to occur on the RS of the weld, which correlates with peak stresses associated with lapshear coupons. Similar to the magnesium sheet failure mode, the crack initiated outside the SZ, 
but at the apex of the cold-lap feature (HAZ region) as seen in Fig. 8b. In lap-shear FSLW, the cold-lap feature leads to a thinning of the sheet, which leads to an increased stress concentration. In addition, at the cold-lap feature, the material strength is significantly lower as observed from the microhardness measurements (Fig. 3). As such, the combination of elevated stress due to sheet thinning and the weaker material strength makes this an ideal location for fatigue crack initiation.

Figure 9a shows a representative cross-sectional view of an interfacial failure mode. In this failure mode, the crack initiated in the weld nugget and propagated through the brittle IMC region. As shown in Fig. 5, many data points on the lower bounds of the scatter are represented by interfacial failure. Figure $9 \mathrm{~b}$ shows a magnified view of the IMC region in the SZ. There is no evidence of secondary crack growth in this mode of failure, thereby strongly suggesting the brittle IMCs in the weld nugget failed to carry the applied load. The presence of micro voids in the weld nugget may also have contributed to early crack initiation in the brittle IMCs and rapid crack propagation resulting in a lower number of cycles compared to the other failure modes.

Figure 10 shows a representative FSLW coupon that failed due to kink-crack growth through the magnesium sheet. For clarification purposes, a 3D representation of the fractured FSLW coupon that exhibited a magnesium sheet failure is shown in Fig. 10a. The fractured magnesium sheet surface in Fig. 10b shows signs of fretting near the faying surface. For further analysis, a portion of the fretting region was imaged via SEM as indicated by the rectangular boxes in Fig. 10b. Figure 10c is a magnified SEM view of the fractured magnesium surface of one of the highlighted regions shown in Fig. 10b, where the dotted line separates the fatigue crack growth and fast fracture regions. The white rectangular boxes indicated by $\mathrm{X} 1, \mathrm{X} 2$, and $\mathrm{X} 3$ show areas on the fractured surface that were of particular interest. Area X1, which is magnified 
and shown in Fig. 10d, illustrates the surface morphology of the fractured surface at the point of fatigue crack initiation. In area X2 (Fig. 10e), the surface morphology shows the typical crack growth region with evidence of twinning (indicated by bold arrows). Area X3 illustrates the fast fracture region and a magnified view of the surface indicates the presence of casting pores as shown in Fig. 10f.

Regarding the location of crack initiation, the faying surface on the aluminum sheet close to the crack initiation region is shown in Fig. 10g, where the presence of oxide debris and an uneven and worn surface suggest fretting initiated the fatigue mechanism. A magnified view of the fretting area reveals thin flakes as displayed in Fig. 10h. EDX analysis of regions P1 and P2 indicated that the debris/flakes were composed of mainly $\mathrm{Al}_{12} \mathrm{Mg}_{17}$ and $\mathrm{Al}_{3} \mathrm{Mg}_{2}$, respectively. The chemical compositions and weight percentages of these regions are provided in Table 1. While we cannot presume a strong correlation between the IMC and fretting fatigue, it is possible that the brittle nature of the IMC layer observed between the magnesium and aluminum sheets (Fig. 4) is more susceptible to fretting-initiated fatigue than the natural oxide layer present on base metal. However, this issue warrants further study that is beyond the scope of this paper.

Figure 11 shows a representative FSLW coupon that failed due to kink-crack growth through the aluminum sheet on the RS of the weld. For coupons that failed due to kink-crack growth in the aluminum sheet, the fracture surface that remained intact to the weld nugget after failure was analyzed, as shown in Fig.11a. Figure 11b is a macro of the fracture surface of a representative FSLW coupon and the black bold arrows in Fig. 11b indicate locations of fretting debris. A magnified view via a SEM of one of these fretting regions is shown in Fig. 11c, where the nature of the kink-crack growth is clearly illustrated. Furthermore, magnified views of areas of interests are indicated by Y1, Y2, and Y3. Figure 11d shows the fractured surface region Y1, 
which is away from the faying surface on the aluminum sheet. This surface clearly shows fatigue striations that are indicative of steady fatigue crack growth and the bold arrow denotes the direction of crack growth. Similar to the kink-crack failure mode of the magnesium sheet, IMCs were present at the fracture surfaces and confirmed by EDX analysis performed at P3 (Fig. 11e.) At the locations of observed fretting debris, several bright regions indicate high levels of oxides, as confirmed with EDX analysis at location P4 shown in Fig. 11f. In addition, the arrows shown in Fig. 11f indicate the direction of crack growth suggesting that a fatigue crack initiated from this bright region. Figure $11 \mathrm{~g}$ shows area Y3 on the aluminum fracture surface, some distance away from the crack initiation region. A magnified view of a small region on this surface is shown in Fig. 11h, where this surface is seen to be marked by the presence of fatigue striations, further supporting the hypothesis that the fatigue crack initiated from the region shown in Fig. $11 \mathrm{f}$.

As discussed earlier, no strong correlation was found regarding the trend of kink-crack fracture of the magnesium and aluminum sheets versus the number of cycles to failure. However, the experimental fatigue results (Fig. 5) show that at fatigue loadings near run-out levels, the predominant crack that led to failure propagated through the aluminum sheet. While, the magnesium sheet was observed to contain casting pores that naturally lower the fatigue crack resistance, it is likely that at these near run-out load levels, the effect of the casting pores was not significant. As such, the thinner aluminum sheet, further thinned by the cold lap-shear feature, experienced higher bending stresses that favor crack initiation into the aluminum sheet compared to the magnesium sheet or the weld nugget. Observations made in this current study regarding the failure of the top sheet on the RS of the weld due to sheet thinning was also observed in fatigue lap-shear testing of FSLW of similar aluminum alloys [38,39]. In addition, a recent work 
by Neik et al. [40] on the fatigue of similar FSLW AZ31 Magnesium alloys showed that fracture under cyclic loading consistently occurred on the AS faying surface in a kinked crack mode and no other failure type was reported. However, we note that these studies did not report finding oxide debris at the location of fatigue crack initiation. This observation seems reasonable since no comparable IMC layer in the similar material joints were reported compared to the dissimilar joint observed in this study. Furthermore, as we will discuss next, the presence of the IMC in the SZ created additional crack initiation sites and propagation pathways that were not observed in similar FSLW overlap joints.

Figure 12 displays a representative FSLW coupon that exhibited an interfacial weld failure. As noted earlier, a majority of the FLSW coupons that were subjected to loads above $2,000 \mathrm{~N}$ failed by interfacial weld separation due to a shear overload. In this mode of failure, the dominant crack propagated through the brittle IMCs in the weld nugget. For the interfacial failure mode, the fracture surfaces of both the aluminum and magnesium sheets were observed under SEM, as shown in Fig. 12a. Macrographs of the fractured weld nugget, on the respective aluminum and magnesium sheets, are shown in Fig. 12b. Four areas of interest including $\mathrm{Z} 1, \mathrm{Z} 2$ on the aluminum sheet and Z3, Z4 on the magnesium sheet were observed under SEM. The fracture surfaces showed signs of cleavage, as expected of a brittle IMC $[19,22,27,41]$. While a fundamentally different type of joint, Chowdhury et al. [30, 42] observed in friction stir spot welding of aluminum-to-magnesium lap-shear joints, the fatigue cracks propagated through the brittle IMC in the stir zone, resulting in nugget failure similar to the observation made in this study. This strongly supports the hypothesis that the brittle IMC can greatly reduce the fatigue life of the dissimilar FSW joints at testing loads approaching the ultimate strength of the joint. 
Further analysis of the fracture surface of the coupons that failed by interfacial weld failure revealed the presence of micro voids in the weld nugget and are indicative of insufficient material mixing. Figure 12c (area Z1) shows voids formed due to insufficient material mixing on the RS of the weld in the aluminum sheet. Fatigue striations can be seen close to the void and the bold arrows indicate the crack propagation direction. Similar voids were also observed close to the AS hook of the aluminum (area Z2), as seen in Fig. 12d. On the magnesium sheet, the nugget portion intact after the failure indicates brittle cleavage failure close to the void on the RS of the sheet (area Z3), as shown in Fig. 12e. Micro voids were also observed in the core of the weld nugget (area Z4), as shown in Fig. 12f.

During fatigue loading, the majority of the load bearing capacity is carried by the weld nugget, and the poor structural integrity caused by such micro voids create high stress concentrations. At higher fatigue loading, a combination of brittle IMCs and micro voids are likely the cause of the observed interfacial weld separation. At lower loads however, the voids seem to act as the points of crack initiation and, from the images in Fig. 12, it is clear that multiple cracks originated in the weld nugget due to presence of micro voids leading to lower fatigue life. Particularly, voids close to AS or the RS hook seem to have a higher influence on crack initiation and propagation compared to micro voids in the core of the weld nugget. However, below fatigue loading of 2,000 $\mathrm{N}$ and when the weld nugget exhibited good structural integrity, the driving force favored fatigue crack initiation away from the weld nugget, which in turn promoted kink crack fracture in the base material. 


\section{Summary}

A study on the mechanical behavior and fracture modes associated with fatigue testing of dissimilar FSLW of aluminum-to-magnesium alloy lap-shear joints was performed. The following summary is presented:

1. The FSLW dissimilar lap-shear coupons exhibited a wide scatter in the fatigue life results. This scatter is a result of several factors including voids and brittle intermetallic compounds that exist due to the metallurgical nature of welding dissimilar metals.

2. The FSLW dissimilar lap-shear coupons exhibited two distinct failure modes: (a) dominant crack propagation through the aluminum or magnesium sheets in kink-crack manner; (b) interfacial failure through the weld nugget.

3. In the aluminum and magnesium sheet failures, oxide debris was observed at the location of crack initiation, which suggests that the cracks initiated due to fretting fatigue. This mode of failure was observed in welds tested below a maximum fatigue load of 2,000 N.

4. The interfacial weld fracture mode was observed throughout the range of fatigue loading. However, this mode of failure was dominant when the applied fatigue loading was above 2,000 N. This indicates that at higher loads the geometrical features of the weld, like the AS and RS hook or the IMCs outside the weld nugget, have little influence on the structural integrity of the weld. Thus, the IMCs in the weld nugget are largely responsible for causing the interfacial fracture.

5. Fractography analysis suggests that insufficient material mixing in some welds resulted in formation of micro voids in the weld nugget, which were directly correlated to underperforming joints. 
6. The current process parameters and tool pin design used to produce the FSLW samples in this current study were shown to break up IMCs in the weld nugget sufficiently well to provide welds that demonstrated a good quasi-static strength. However, the amount of this breaking up the IMCs is not good enough to allow a commensurately good fatigue life for all samples. When the stress is directed through the nugget, the IMCs and microvoids formed due to insufficient material mixing lead to lower fatigue life.

7. Furthermore, the IMCs formed outside the stir zone (along the faying surface) lead to fretting damage outside the weld. This in turn reduced the fatigue life, as the fretting cause one or the other sheets to fail in a kink-crack fashion. The IMCs outside the stir zone were never expected to affect the quasi-static load-bearing capacity of the joint. However, their presence has proved to be a detriment to fatigue performance.

\section{Acknowledgements}

The authors would like to recognize of the United States Automotive Materials partnership (USAMP) Magnesium Front End R\&D project, including Joy Forsmark, Jim Quinn and Robert McCune, for their helpful discussions. This material is based upon work supported by the Department of Energy, National Energy Technology Laboratory under Award Number No. DEEE0005660. This report was prepared as an account of work sponsored by an agency of the United States Government. Neither the United States Government nor any agency thereof, nor any of their employees, makes any warranty, express or implied, or assumes any legal liability or responsibility for the accuracy, completeness, or usefulness of any information, apparatus, product, or process disclosed, or represents that its use would not infringe privately owned rights. Reference herein to any specific commercial product, process, or service by trade name, trademark, manufacturer, or otherwise does not necessarily constitute or imply its endorsement, 
recommendation, or favoring by the United States Government or any agency thereof. The views and opinions of authors expressed herein do not necessarily state or reflect those of the United States Government or any agency thereof. Such support does not constitute an endorsement by the Department of Energy of the work or the views expressed herein. This work utilized resources owned and maintained by the Central Analytical Facility, which is supported by The University of Alabama.

\section{References}

[1] Yang Q, Li X, Chen K, Shi YJ. Effect of tool geometry and process condition on static strength of a magnesium friction stir lap linear weld. Mater Sci Eng A 2011;528:2463-78.

[2] Yuan W, Carlson B, Verma R, Szymanski R. Study of top sheet thinning during friction stir lap welding of AZ31 magnesium alloy. Sci Technol Weld Join 2012;17:375-80.

[3] Buffa G, Campanile G, Fratini L, Prisco a. Friction stir welding of lap joints: Influence of process parameters on the metallurgical and mechanical properties. Mater Sci Eng A 2009;519:19-26.

[4] Afrin N, Chen DLL, Cao X, Jahazi M. Microstructure and tensile properties of friction stir welded AZ31B magnesium alloy. Mater Sci Eng A 2008;472:179-86.

[5] Xunhong W, Kuaishe W. Microstructure and properties of friction stir butt-welded AZ31 magnesium alloy. Mater Sci Eng A 2006;431:114-7.

[6] Yadava MK, Mishra RS, Chen YL, Carlson B, Grant GJ. Study of friction stir joining of thin aluminium sheets in lap joint configuration. Sci Technol Weld Join 2010;15:70-5.

[7] Chowdhury SH, Chen DL, Bhole SD, Cao X, Wanjara P. Friction Stir Welded AZ31 Magnesium Alloy: Microstructure, Texture, and Tensile Properties. Metall Mater Trans A 2012;44:41-4.

[8] Chowdhury SM, Chen DL, Bhole SD, Cao X. Tensile properties of a friction stir welded magnesium alloy: Effect of pin tool thread orientation and weld pitch. Mater Sci Eng A 2010;527:6064-75.

[9] Rao HM, Jordon JB, Barkey ME, Guo YB, Su X, Badarinarayan H. Influence of structural integrity on fatigue behavior of friction stir spot welded AZ31 Mg alloy. Mater Sci Eng A 2013;564:369-80. 
[10] Rao HM, Rodriguez RI, Jordon JB, Barkey ME, Guo YB, Badarinarayan H, et al. Friction stir spot welding of rare-earth containing ZEK100 magnesium alloy sheets. Mater Des 2014;56:750-4.

[11] Rodriguez RI, Jordon JB, Rao HM, Badarinarayan H, Yuan W, El Kadiri H, et al. Microstructure, texture, and mechanical Properties of friction stir spot welded rare-earth containing magnesium ZEK100 alloy sheets. Mater Sci Eng A 2014;618:637-44.

[12] Jordon JB, Horstemeyer MF, Daniewicz SR, Badarinarayan H, Grantham J. Fatigue Characterization and Modeling of Friction Stir Spot Welds in Magnesium AZ31 Alloy. J Eng Mater Technol 2010;132:041008.

[13] Choi DH, Ahn BW, Lee CY, Yeon YM, Song K, Jung SB. Formation of intermetallic compounds in $\mathrm{Al}$ and $\mathrm{Mg}$ alloy interface during friction stir spot welding. Intermetallics 2011;19:125-30.

[14] Yamamoto N, Liao J, Watanabe S, Nakata K. Effect of Intermetallic Compound Layer on Tensile Strength of Dissimilar Friction-Stir Weld of a High Strength Mg Alloy and Al Alloy. Mater Trans 2009;50:2833-8.

[15] McLean AA, Powell GLF, Brown IH, Linton VM. Friction stir welding of magnesium alloy AZ31B to aluminium alloy 5083. Sci Technol Weld Join 2003;8:462-4.

[16] Chen YC, Nakata K. Friction stir lap joining aluminum and magnesium alloys. Scr Mater 2008;58:433-6.

[17] Kwon YJ, Shigematsu I, Saito N. Dissimilar friction stir welding between magnesium and aluminum alloys. Mater Lett 2008;62:3827-9.

[18] Firouzdor V, Kou S. Formation of Liquid and Intermetallics in Al-to-Mg Friction Stir Welding. Metall Mater Trans A 2010;41:3238-51.

[19] Hirano S, Okamoto K, Doi M, Okamura H, Inagaki M, Aono Y. Microstructure of dissimilar joint interface of magnesium alloy and aluminum alloy by friction stir welding. Q J Japan Weld Soc 2003;21:539-45.

[20] Gerlich A, Su P, North TH, Bendzsak GJ. Friction stir spot welding of aluminum and magnesium alloys. Mater. forum, vol. 29, 2005, p. 290-4.

[21] Kou S. Al-to-Mg Friction Stir Welding : Effect of Positions of Al and Mg with Respect to the. Weld J 2009;88:213-24.

[22] Sato YS, Park SHC, Michiuchi M, Kokawa H. Constitutional liquation during dissimilar friction stir welding of Al and Mg alloys. Scr Mater 2004;50:1233-6. 
[23] Kostka A, Coelho R., dos Santos J, Pyzalla A. Microstructure of friction stir welding of aluminium alloy to magnesium alloy. Scr Mater 2009;60:953-6.

[24] Cao XJ, Jahazi M. Friction Stir Welding of Dissimilar AA 2024-T3 to AZ31B-H24 Alloys. Mater Sci Forum 2010;638-642:3661-6.

[25] Kimapong K, Watanabe T. Effect of Welding Process Parameters on Mechanical Property of FSW Lap Joint between Aluminum Alloy and Steel. Mater Trans 2005;46:2211-7.

[26] Chen YC, Nakata K. Effect of tool geometry on microstructure and mechanical properties of friction stir lap welded magnesium alloy and steel. Mater Des 2009;30:3913-9.

[27] Rao HM, Yuan W, Badarinarayan H. Effect of process parameters on mechanical properties of friction stir spot welded magnesium to aluminum alloys. Mater Des 2015;66:235-45.

[28] Yuan W, Badarinarayan H, Rao HM. "Friction stir welding of dissimilar aluminum and magnesium alloys for automotive sub-structure. 10th Frict. Stir Weld. Symp., Bejing: 2014.

[29] Rao HM. A Fundamental Study on the Structural Integrity of Magnesium Alloys Joined by Friction Stir Welding. The University of Alabama, 2014.

[30] Chowdhury SH, Chen DL, Bhole SD, Cao X, Wanjara P. Lap shear strength and fatigue life of friction stir spot welded AZ31 magnesium and 5754 aluminum alloys. Mater Sci Eng A 2012;556:500-9.

[31] Cavaliere P, Panella F. Effect of tool position on the fatigue properties of dissimilar 20247075 sheets joined by friction stir welding. J Mater Process Technol 2008;206:249-55.

[32] Cavaliere P, Nobile R, Panella FW, Squillace a. Mechanical and microstructural behaviour of 2024-7075 aluminium alloy sheets joined by friction stir welding. Int J Mach Tools Manuf 2006;46:588-94.

[33] Tran V, Pan J, Pan T. Fatigue behavior of aluminum 5754-O and 6111-T4 spot friction welds in lap-shear specimens. Int J Fatigue 2008;30:2175-90.

[34] Scialpi A, De Giorgi M, De Filippis LAC, Nobile R, Panella FW. Mechanical analysis of ultra-thin friction stir welding joined sheets with dissimilar and similar materials. Mater Des 2008;29:928-36.

[35] Lombard H, Hattingh DG, Steuwer A, James MN. Optimising FSW process parameters to minimise defects and maximise fatigue life in 5083-H321 aluminium alloy. Eng Fract Mech 2008;75:341-54. 
[36] Uematsu Y, Tozaki Y, Tokaji K, Nakamura N. Fatigue Behavior of Dissimilar Friction Stir Welds Between Cast and Wrought Aluminum Alloys. Strength Mater 2008;40:13841.

[37] Nandan R, Debroy T, Bhadeshia H. Recent advances in friction-stir welding - Process, weldment structure and properties. Prog Mater Sci 2008;53:980-1023.

[38] Ericsson M, Jin L, Sandstrom R. Fatigue properties of friction stir overlap welds. Int J Fatigue 2007;29:57-68.

[39] Xu X, Yang X, Zhou G, Tong J. Microstructures and fatigue properties of friction stir lap welds in aluminum alloy AA6061-T6. Mater Des 2012;35:175-83.

[40] Naik BS, Chen DL, Cao X, Wanjara P. Microstructure and fatigue properties of a friction stir lap welded magnesium alloy. Metall Mater Trans A Phys Metall Mater Sci 2013;44:3732-46.

[41] Yamamoto M, Gerlich a., North TH, Shinozaki K. Cracking in dissimilar Mg alloy friction stir spot welds. Sci Technol Weld Join 2008;13:583-92.

[42] Chowdhury SH, Chen DL, Bhole SD, Cao X, Wanjara P. Lap shear strength and fatigue behavior of friction stir spot welded dissimilar magnesium-to-aluminum joints with adhesive. Mater Sci Eng A 2013;562:53-60. 
Table 1: The compositions (weight \%) measured using EDX at various locations in the fretting regions.

\begin{tabular}{cccccc}
\hline Region & Phase & $\mathbf{M g}($ Wt. \%) & Al $($ Wt. \%) & O (Wt. \%) & Total \\
\hline P1 & $\mathrm{Al}_{3} \mathrm{Mg}_{2}+$ oxide & 29.5 & 57.0 & 13.5 & 100.0 \\
\hline P2 & $\mathrm{Al}_{12} \mathrm{Mg}_{17}$ & 71.8 & 20.6 & 7.6 & 100.0 \\
\hline P3 & $\mathrm{Al}_{12} \mathrm{Mg}_{17}$ & 54.0 & 43.6 & 2.3 & 100.0 \\
\hline P4 & $\mathrm{Al}_{3} \mathrm{Mg}_{2}+$ oxide & 37.4 & 40.1 & 22.5 & 100.0 \\
\hline
\end{tabular}



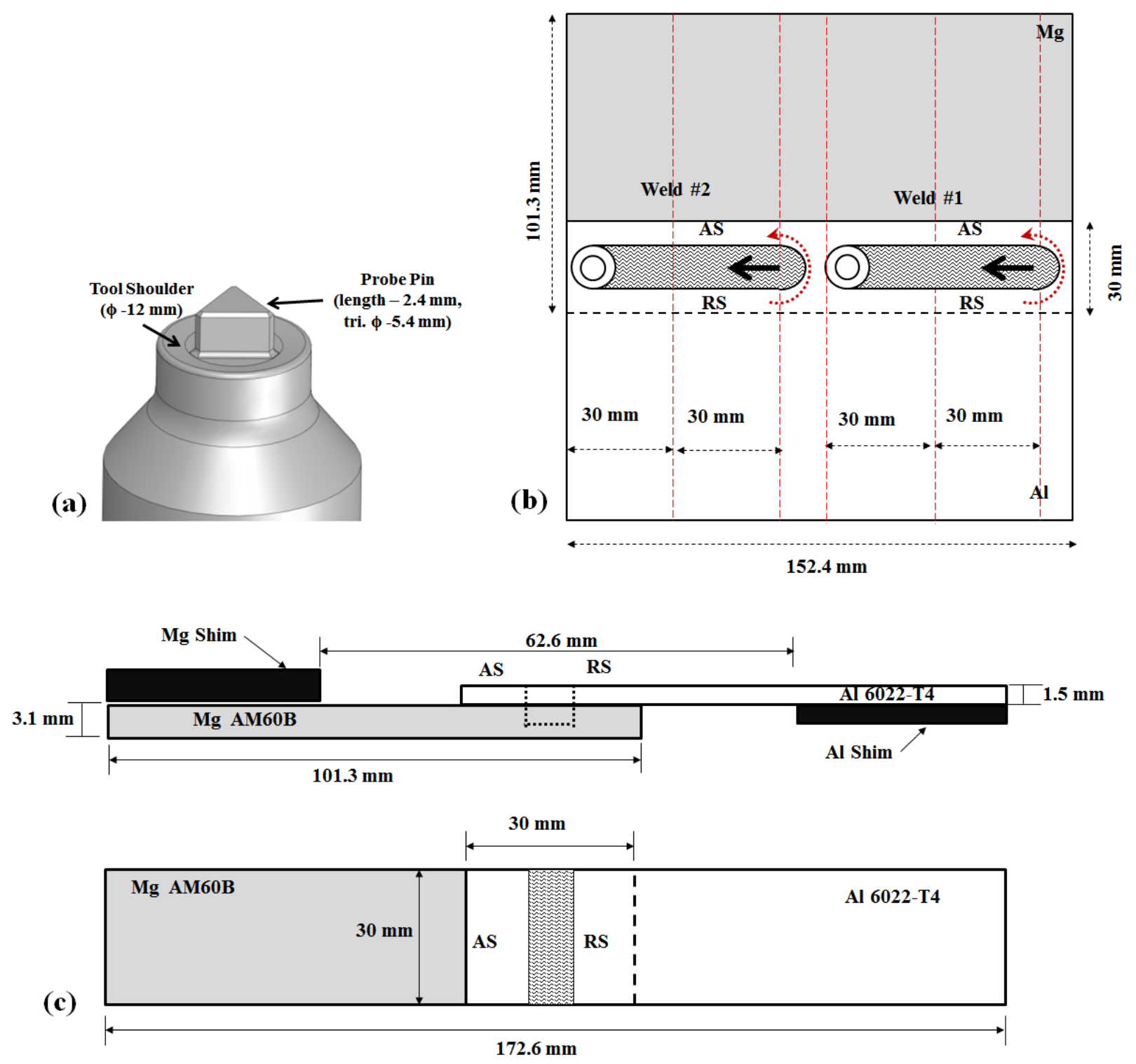

Figure 1: Representations of (a) the FSLW tool profile; (b) the FSLW samples indicating the tool traverse direction (bold arrows), tool rotation direction (dotted arrows) and geometrical dimensions of the materials used, and (c) geometrical dimensions of the FSLW test coupons after being water-jet cut 


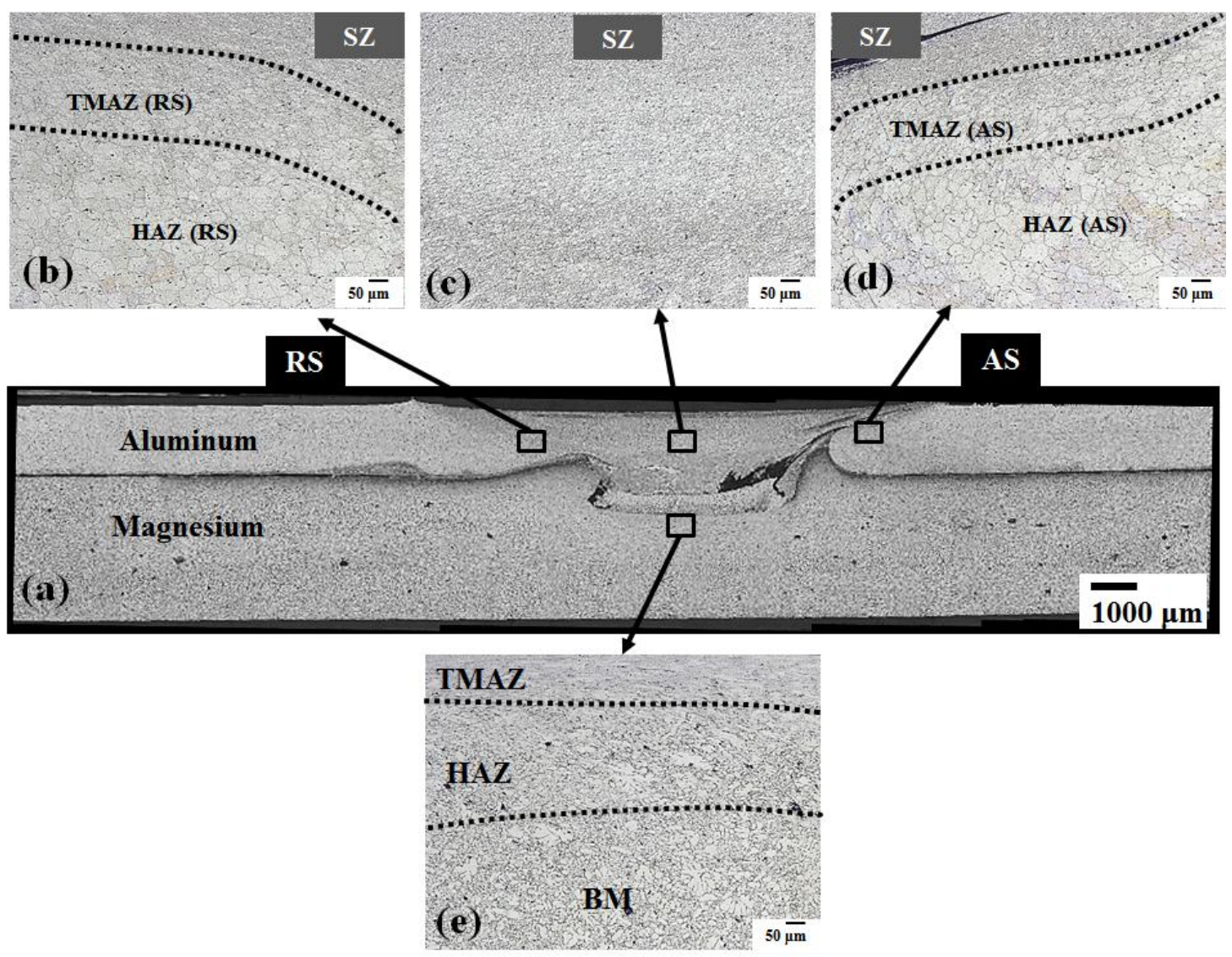

Figure 2: Microstructures of the various regions in the weld: (a) cross-section view of a representative untested FLSW coupon; (b) transition from SZ to TMAZ to HAZ on RS of weld in the aluminum sheet; (c) SZ in the aluminum sheet; (d) transition from SZ to TMAZ to HAZ on AS of weld in the aluminum sheet (e) TMAZ, HAZ and BM region in the magnesium sheet. 


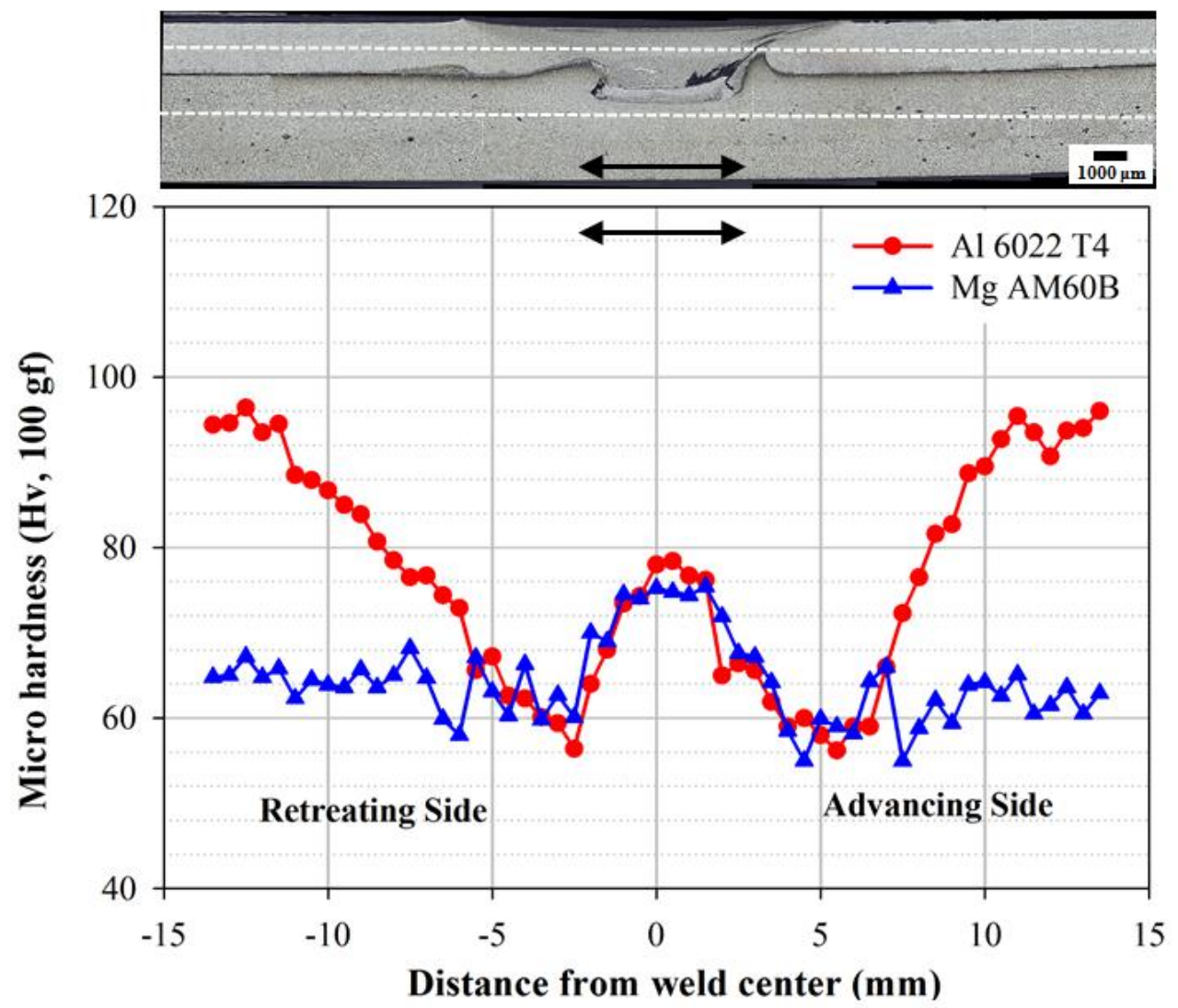

Figure 3: Microhardness profiles across the FLSW aluminum-to-magnesium lap-shear coupon:

(a) the dashed lines indicate where the hardness measurements were performed; (b) the plot comparing the Vickers hardness of the top aluminum and bottom magnesium sheets. 

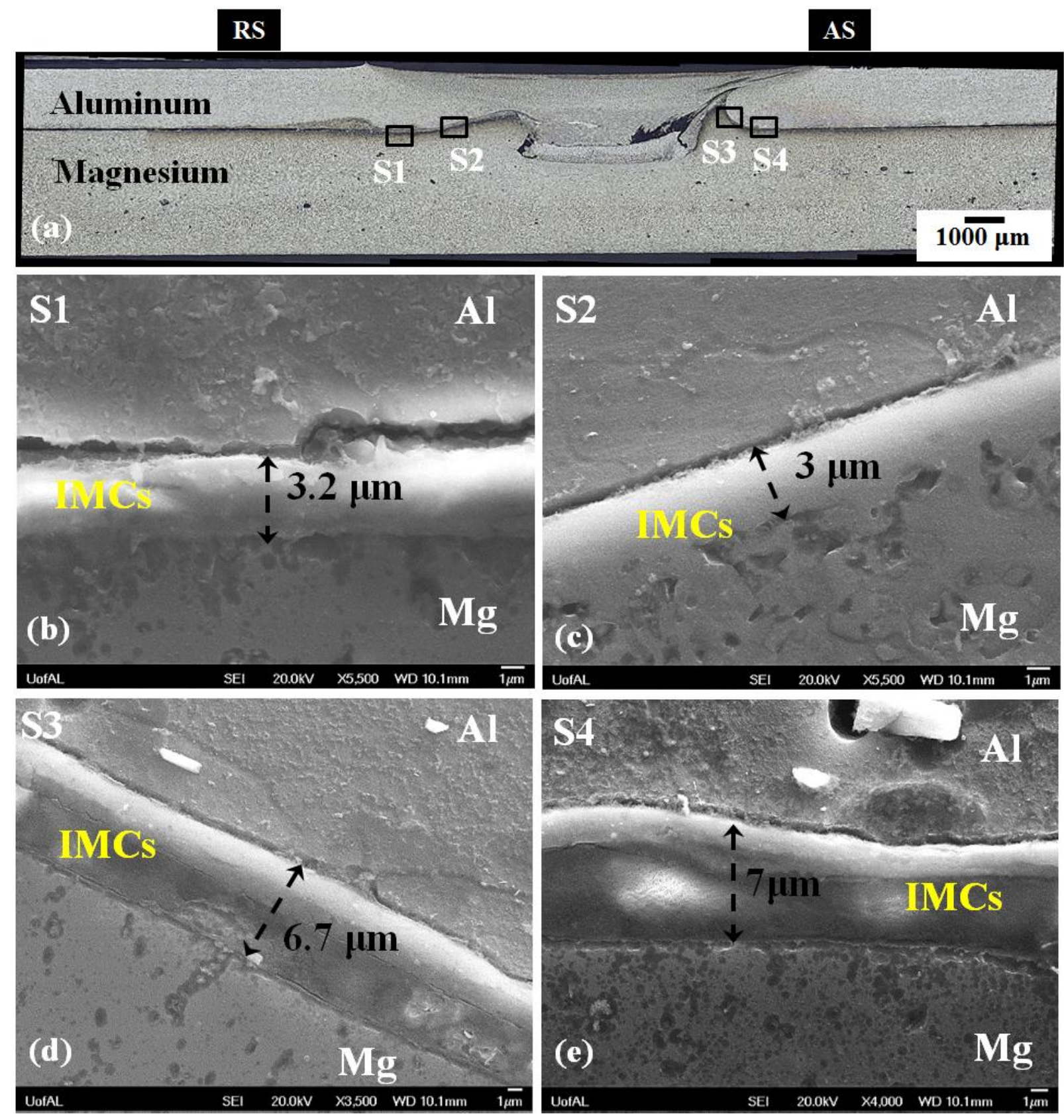

Figure 4: SEM images of the IMCs on the faying surface in the FSLW: (a) representative crosssection of an untested coupon indicating regions of interest; (b) magnified view of region S1 on the RS; (c) magnified view of region S2 on the RS; (d) magnified view of region S3 on the AS; and (e) magnified view of region S4 on the AS of the weld. 


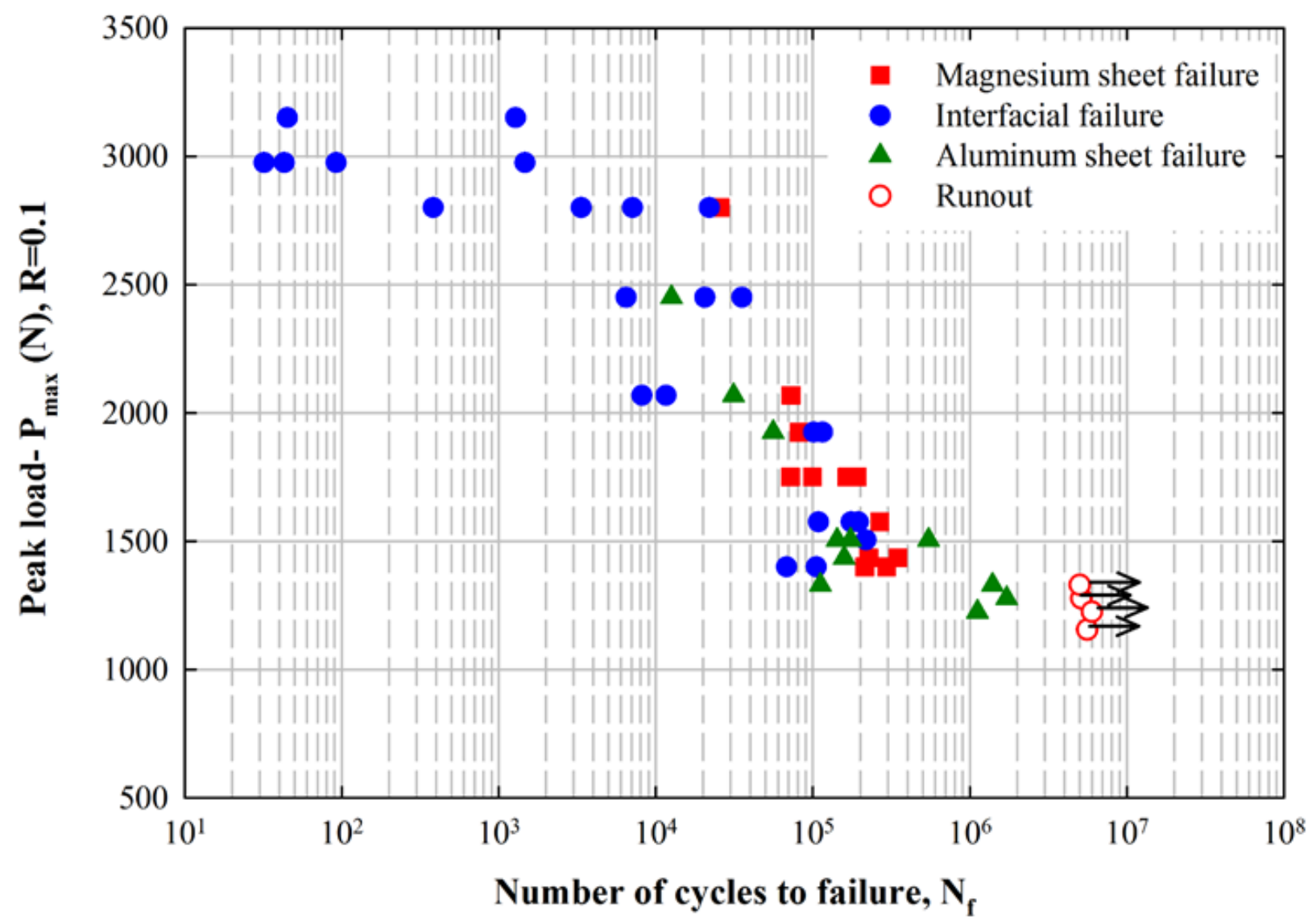

Figure 5: Experimental results of fatigue testing of FSLW aluminum-to-magnesium lap-shear coupons indicating the different failure modes.

Retreating side

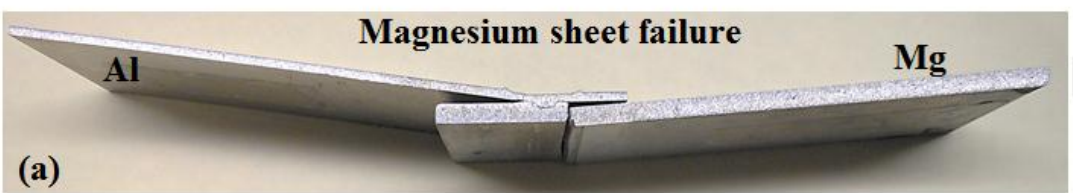

(a)

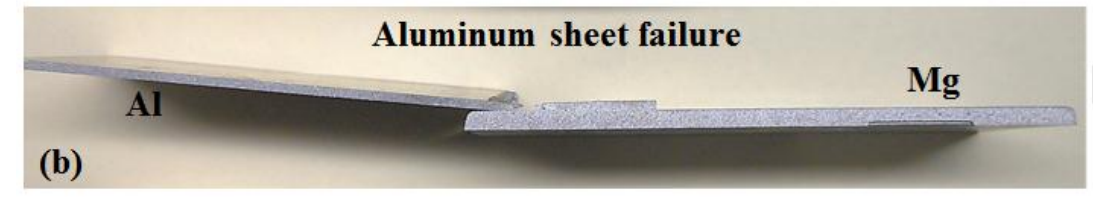

\section{Aluminum sheet failure}

\section{Interfacial failure}

Al

(c)

Figure 6: Failure modes of the FSLW lap-shear coupons: (a) magnesium sheet failure; (b) aluminum sheet failure; and (c) interfacial weld failure. 

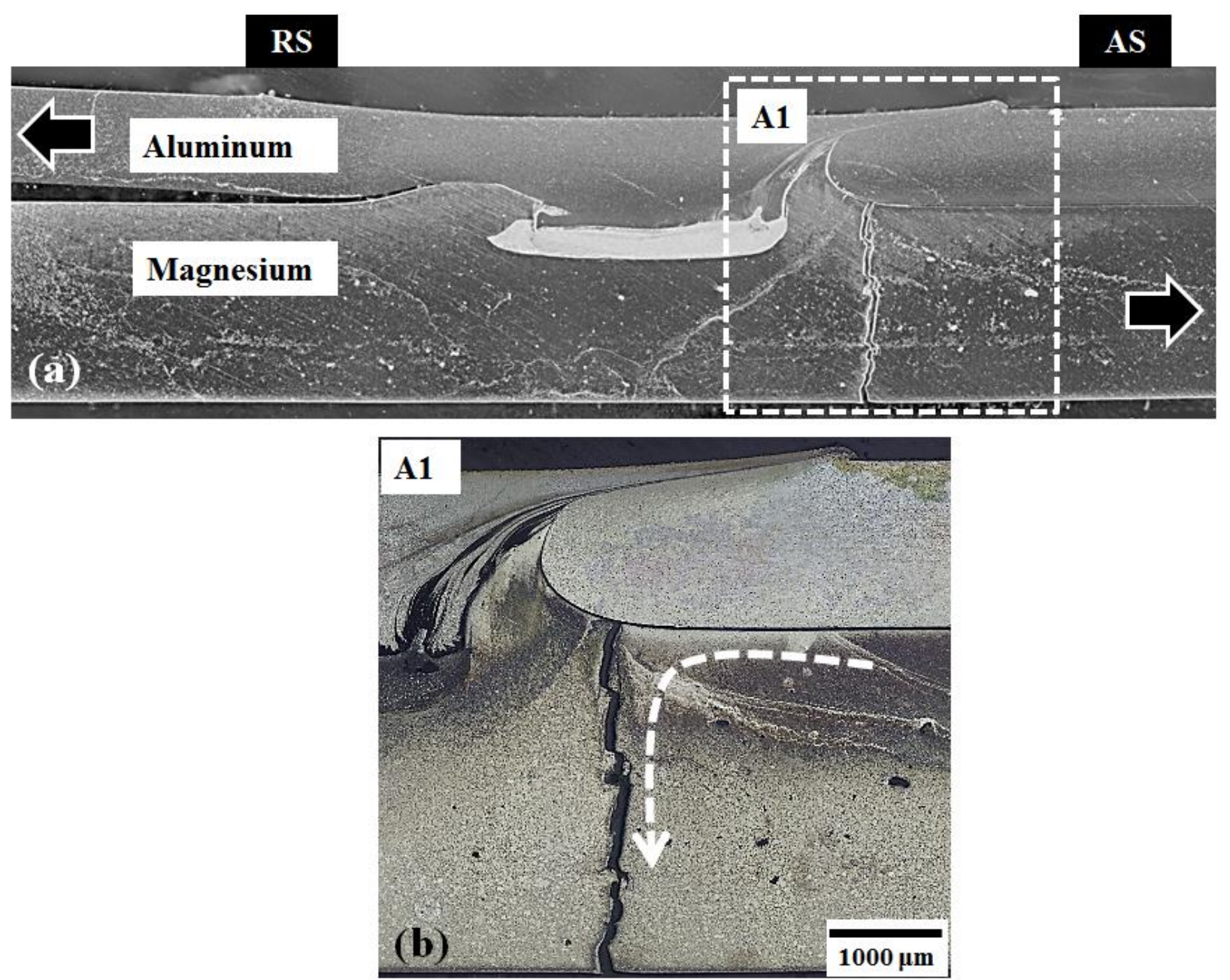

Figure 7: Representative magnesium sheet failure in FSLW lap-shear coupons: (a) overview of a FSLW coupon, where the dotted box indicates the failure region A1; (b) magnified view of region $\mathrm{A} 1$, which clearly shows that the dominant crack propagated through the magnesium sheet. 

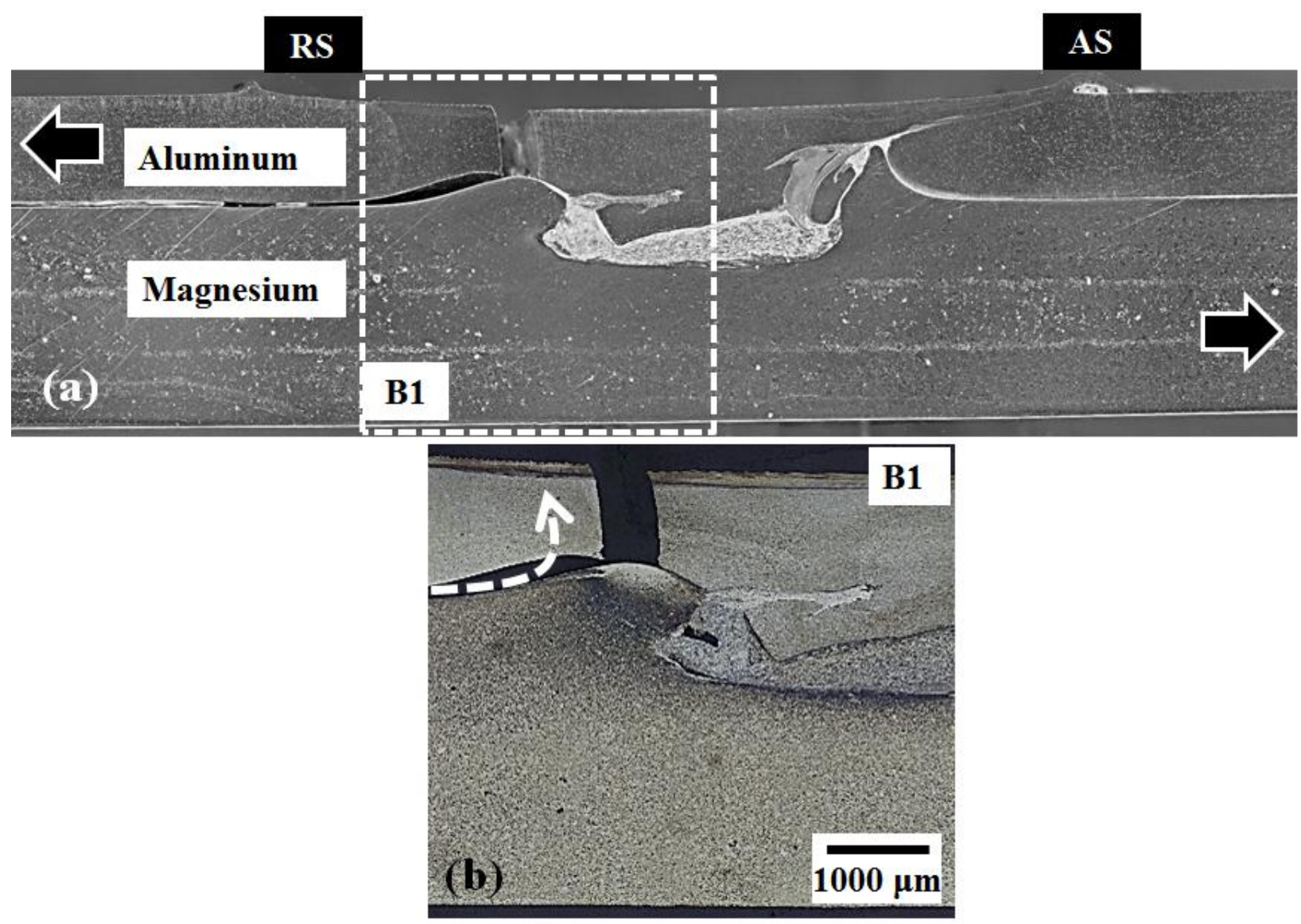

Figure 8: Representative aluminum sheet failure in FSLW lap-shear coupon: (a) overview of a FSLW coupon, where the dotted box indicates the failure region B1; (b) magnified view of region $\mathrm{B} 1$, which clearly shows that the dominant crack propagated through the aluminum sheet. 

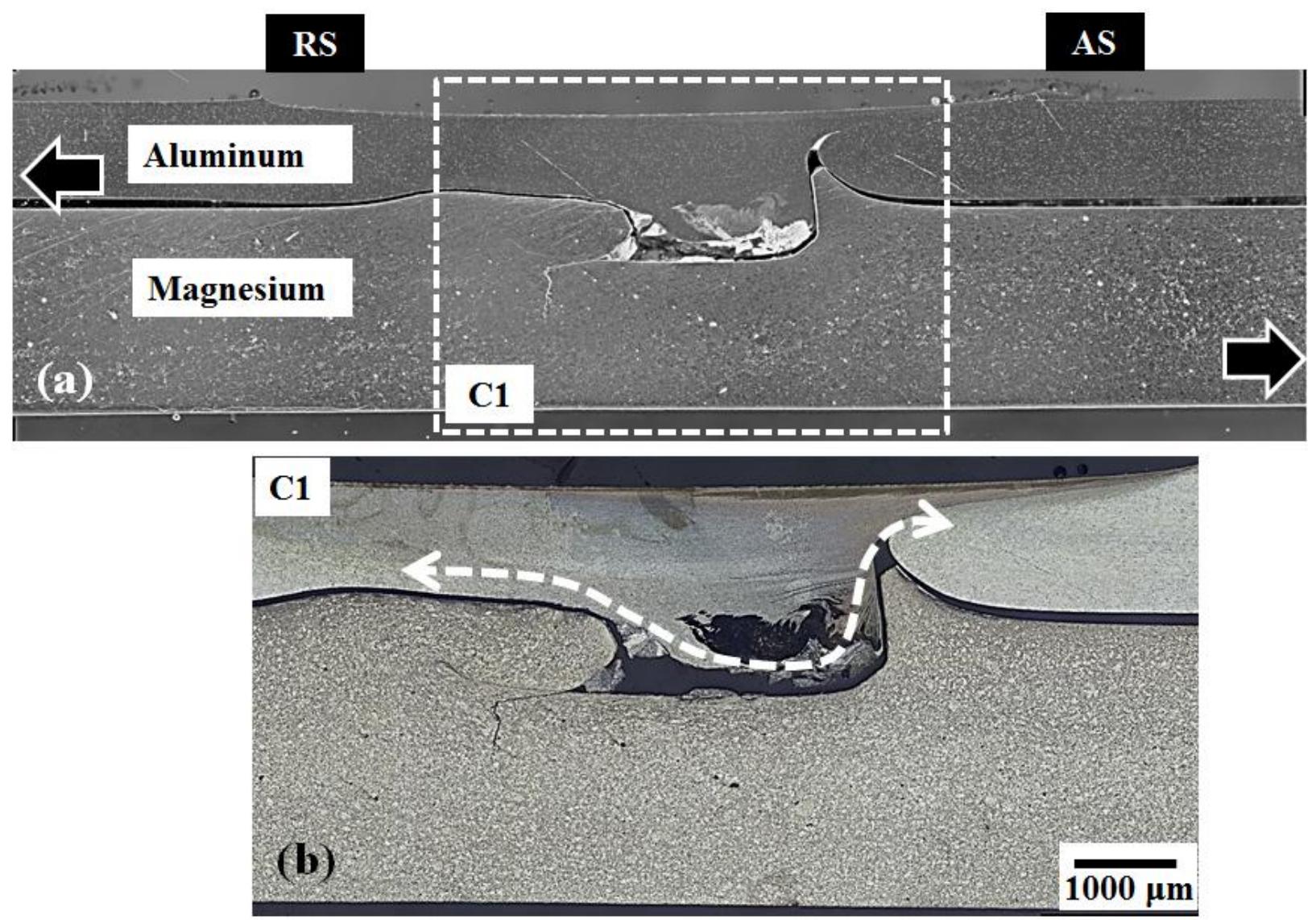

Figure 9: Representative interfacial failure in FSLW lap-shear coupon: (a) overview of a FSLW coupon, where the dotted box indicates the failure region $\mathrm{C} 1$; (b) magnified view of region $\mathrm{C} 1$, which clearly shows that the dominant crack propagated through the weld nugget. 


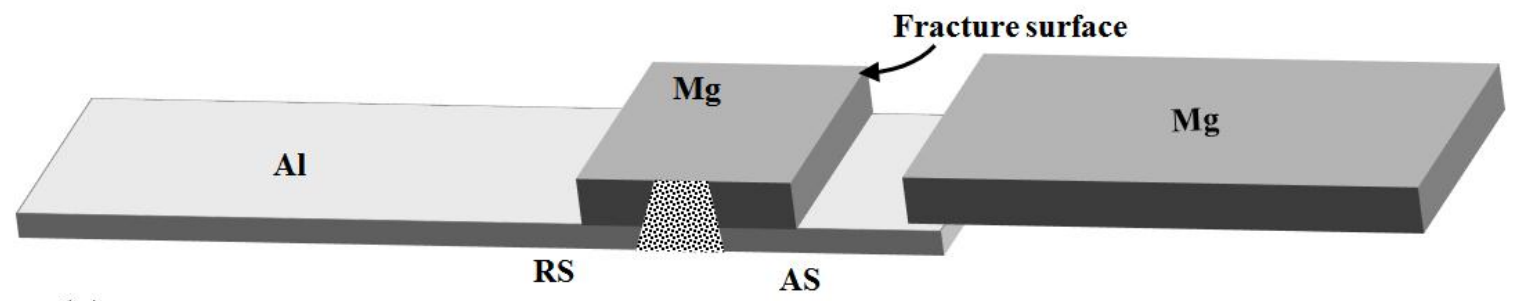

(a)

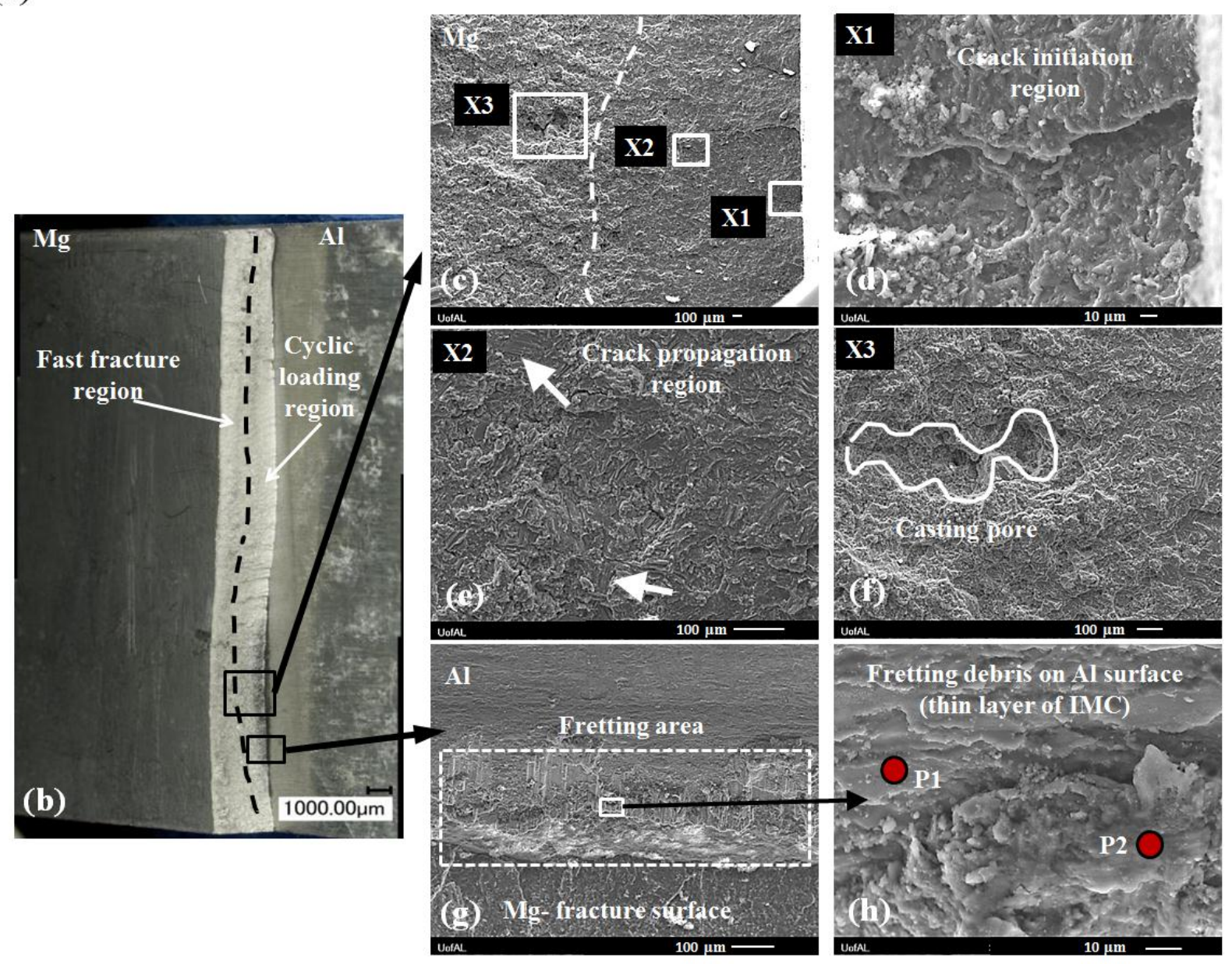

Figure 10: Fracture surface analysis of a representative weld coupon which that failed due to kink crack growth in the magnesium sheet: (a) 3D representation of the magnesium sheet failure indicating the surface where fracture analysis using SEM was performed; (b) macrograph of the magnesium sheet fracture surface; (c) overview of a small region on the fracture surface indicating areas of interest X1, X2 and X3 which are of interest; (d) magnified area X1 showing the crack initiation region close to the faying surface; (e) magnified area X2 on the fracture surface, arrows indicate the crack propagation region; (f) magnified area X3 on the fast fracture region showing the casting pores in magnesium; $(\mathrm{g})$ overview of the fretting region on the aluminum surface close to the crack initiation point; (h) magnified view of the fretting debris on the aluminum surface; and dotted circles P1 and P2 indicate the EDX analysis region. 


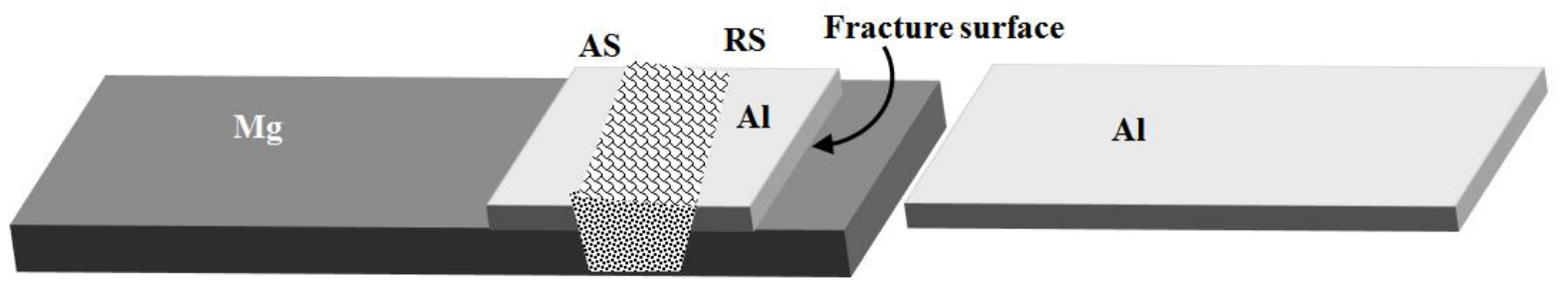

(a)

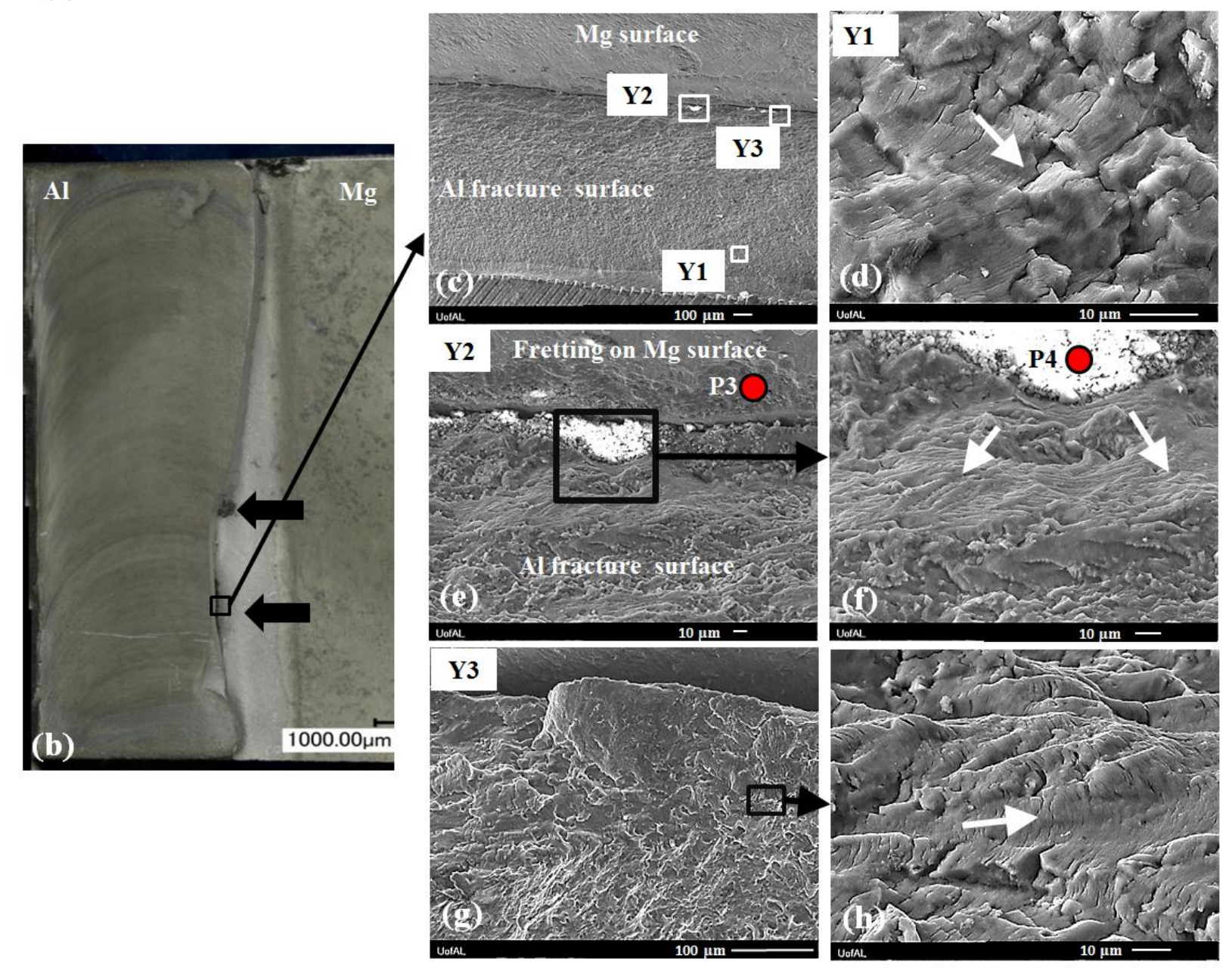

Figure 11: Fracture surface analysis of a representative weld coupon that failed due to kink crack growth in the aluminum sheet: (a) 3D representation of the aluminum sheet failure indicating the surface where fracture analysis using SEM was performed; (b) macrograph of the aluminum sheet fracture surface; (c) overview of a small region on the fracture surface indicating areas of interest Y1, Y2 and Y3; (d) magnified area Y1, which is away from the faying surface, showing the fatigue striations in the region; arrow points the crack propagation direction; (e) magnified area Y2 on the fracture surface close to faying surface on the fractured aluminum surface; (f) magnified area of Y2 very close to the faying surface where the dominant crack initiated; arrows indicate the crack propagation direction; (g) area Y3 close to faying surface and away from the fretting region; (h) magnified view of the area Y3 showing the presence of fatigue striations; white bold arrow points the direction of crack propagation; circles P3 in (e) and P4 in (f) indicate the EDX analysis region. 

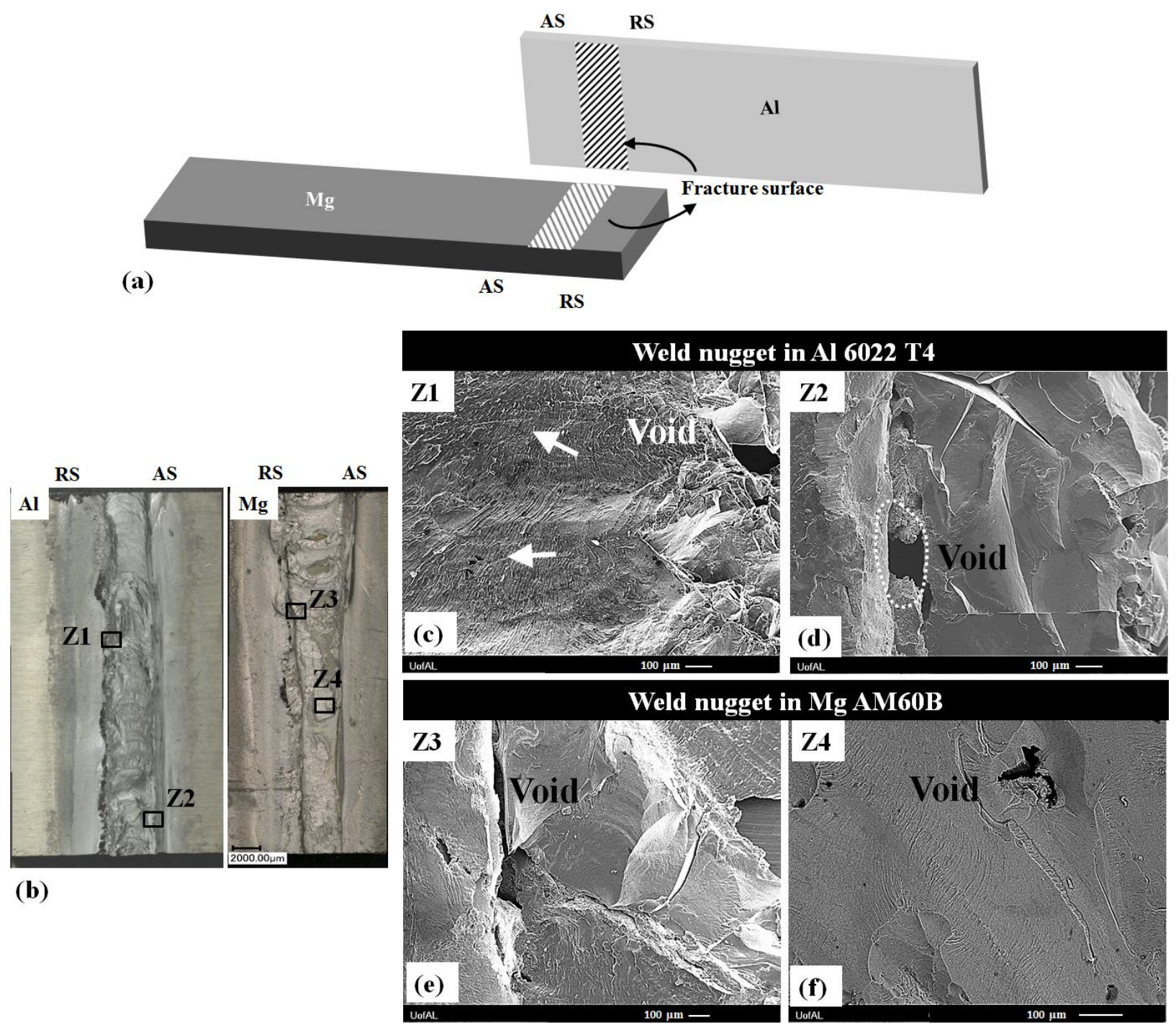

Figure 12: Fracture surface analysis of a representative weld coupon that failed due to interfacial failure along the weld nugget: (a) 3D representation of the interfacial failure indicating the surface where fracture analysis using SEM was performed; (b) macrographs of the aluminum and magnesium fracture surfaces along the weld nugget; (c) magnified view of the area Z1 on the weld RS of the nugget portion that remained on the aluminum side upon fatigue failure, showing the weld voids and bold arrows indicate the crack propagation direction; (d) area Z2 on the AS of the weld nugget portion that remained on the aluminum, showing the weld voids and brittle fracture surface; (e) area Z3 on the RS of weld nugget portion that remained on the magnesium, showing weld voids in the region; (f) area $\mathrm{Z4}$ on the weld nugget portion that remained on the magnesium showing the weld voids. 